\title{
STUDI KOMPARASI KETERCAPAIAN HASIL UJIAN AKHIR NASIONAL IPA PROGRAM REGULER DAN INTERNASIONAL SMP KRISTEN KALAM KUDUS SURAKARTA
}

\author{
Richard Dharma Anggada ${ }^{1}$, Risya Pramana Situmorang ${ }^{2}$, Lusiawati Dewi ${ }^{3}$ \\ Program Studi Pendidikan Biologi, Universitas Kristen Satya Wacana \\ Email : richardsuwitowidjojo @gmail.com
}

\begin{abstract}
Abstrak
Penelitian ini bertujuan untuk untuk mengetahui perbandingan antara program internasional dan reguler terhadap ketercapaian ujian akhir dari peserta didik di SMP Kristen Kalam Kudus Surakarta.Hasil ujian nasional Ilmu Pengetahuan Alam (IPA) dari tahun 2012-2017 digunakan untuk membandingkan kedua program berdasarkan uji statistik Mann-Whitney sebagai dasar pengambilan keputusan. Selain itu, dilakukan analisis faktor yang mempengaruhi ketercapaian hasil belajar yang meliputi: sarana prasarana, kompetensi profesional guru, dan ketercapaian kurikulum didapatkan melalui angket yang diberikan kepada guru IPA dan observasi. Berdasarkan uji Mann-Whitney, nilai P uji kedua kelompok ini sebesar 0.005 (sig. < 0.05) dari rata-rata program internasional yaitu 81.45 yang lebih besar dibandingkan ratarata program reguler yaitu 78.32. Perbedaan hasil belajar tersebut dipengaruhi oleh beberapa faktor seperti sarana prasarana, kompetensi profesional guru, dan ketercapaian kurikulum. Program internasional cenderung lebih baik pada ketiga faktor tersebut dibandingkan program reguler meskipun ketercapaian nilai UN IPA antar tahun pelajaran dari program internasional menunjukkan tren menurun apabila dibandingkan dengan tren program reguler yang cenderung meningkat. Analisis terhadap faktor yang mempengaruhi hasil belajar menunjukkan bahwa sarana prasarana, kompetensi professional guru, dan ketercapaian kurikulum akan mempengaruhi ketercapaian pembelajaran peserta didik.
\end{abstract}

Kata kunci : program kelas reguler, program internasional

\section{COMPARATIVE STUDY OF ACHIEVEMENT OF NATIONAL FINAL EXAM FOR NATURAL SCIENCE REGULAR AND INTERNATIONAL PROGRAM ON KALAM KUDUS CHRISTIAN JUNIOR HIGH SCHOOL IN SURAKARTA}

\author{
Richard Dharma Anggada ${ }^{1}$, Risya Pramana Situmorang ${ }^{2}$, Lusiawati Dewi ${ }^{3}$ \\ Department of Educational Biology, Satya Wacana Christian University \\ Email : richardsuwitowidjojo@gmail.com
}

\begin{abstract}
The purpose of this research was to find out the differences between international and regular program based on national final test result at Kalam Kudus Christian Junior High School students. Natural science national final test results from 2012-2017 was used to compare these programs based on Mann-Whitney statistical test as basic decisions. In addition, the analysis of factors that affect the learning outcomes such as: facilities, professional competence of teachers, and the achievement of the curriculum obtained through a questionnaire given to science teachers and observation. Based on the Mann-Whitney test, the P value of both groups test is 0.005 (sig. <0.05) from the international program average of 81.45 which is higher than the regular program average of 78.32. The differences in learning outcomes are influenced by several factors such as facilities, professional teacher competence, and curriculum achievement. Trend of International program is better than regular programs based on three factors, although the achievement of the natural science national final testscore between the lessons of the international program shows a downward trend when compared to the trend of regular programs that tend to increase. Analysis of the factors that influence the learning outcomes shows that the infrastructure, professional competence of teachers, and the achievement of the curriculum will affect the learning achievement of learners.
\end{abstract}

Keywords: regular program, international program 


\section{PENDAHULUAN}

Pendidikan bagi setiap individu khususnya bagi setiap anak karena menjadi kebutuhan yang sangat penting dalam membentuk perkembangan, kemampuan dan keterampilan peserta didik pada saat dewasa nantinya.Hal tersebut senada dengan pendapat salah satu tokoh pendidikan nasional, K. H. Dewantara yang menyatakan bahwa pendidikan adalah daya upaya untuk memajukan budi pekerti, pikiran, serta jasmani anak, agar dapat memajukan kesempurnaan hidup yaitu hidup dan menghidupkan anak yang selaras dengan alam dan masyarakatnya(Meilani, 2011).

Pemerintah Indonesia merumuskan definisi pendidikan dalam Undang-Undang No. 20 tahun 2003 tentang Sistem Pendidikan Nasionaladalah usaha sadar terencana untuk mewujudkan suasana belajar dan proses pembelajaran agar peserta didik secara aktif mengembangkan potensi dirinya untuk memiliki kekuatan spiritual keagamaan, pengendalian diri, kepribadian, kecerdasan, akhlak mulia, serta keterampilan yang diperlukan darinya, masyarakat, bangsa, dan negara.Secara keseluruhan pendidikan dapat didefinisikan menjadi kebutuhan seluruh siswa karena menjadi wadah untuk memfasilitasi perkembangan diri, kepribadian, dan potensi diri yang perlu digali untuk memberikan kontribusi yang berarti bagi kesejahteraan diri dan masyarakat pada umumnya.

Namun proses dan upaya dalam meningkatkan kualitas pendidikan menjadi lebih baik lagidalam membentuk kecakapan yang fundamental serta memajukan budi pekerti masih terus dilakukan untuk menghadapi tantangan-tantangan sesuai dengan perkembangan zaman.Pada era globalisasi di abad ke-21 ini, kemajuan Ilmu Pengetahuan danTeknologi (IPTEK), misalnya kemudahan mendapat informasi menjadi salah satu tantangan yang harus dijawab untuk dapat memberikan pendidikan yang semakin layak kepada para peserta didik sehingga idealisme pendidikan yang dicetuskan para ahli dan pemerintah dapat tercapai tanpa meninggalkan jati diri bangsa melalui berbagai jenjang pendidikan formal (Mukminan, 2014).Menurut Sa'ud dan Sumantri (2007), peningkatan mutu dan relevansi serta efisiensi manajemen pendidikan dapat dilakukan untuk menjawab tantangan pendidikan di abad ke21, terkhusus pada pendidikan tingkat menengah di Indonesia.Peningkatan efisiensi manajemen pendidikan dapat dilakukan melalui penerapan manajemen berbasis sekolah dan pembaharuan pengelolaan pendidikan secara terencana, terarah, dan berkesinambungan seperti yang diatur dalam Peraturan Menteri Pendidikan No. 22 tahun 2006.

Tuntutan perkembangan zaman tersebut juga berdampak pada pendidikan 
tingkat menengah di Indonesia, menurut Murdiono yang dikutip oleh Wuradji (2015), tantangan terbesar yang dihadapi dunia pendidikan Indonesia adalah bagaimana mengembangkan kreativitas dan prakarsa peserta didik sehingga masa persiapan mereka dapat dilaksanakan dengan baik dan siap untuk menghadapi tantangan di era globalisasi, belum adanya pemerataan pendidikan tingkat menengah dalam segi sarana dan prasarana penunjang kegiatan belajar mengajar menjadi hambatan utama untuk mampu mengembangkan kreativitas dan prakarsa peserta didik

Salah satu upaya dalam menjawab kebutuhan pendidikan di era globalisasi, Sekolah Menengah Pertama Kristen Kalam Kudus (SMPK KK) Surakarta menyediakan 2 (dua) program pendidikan, yaitu kelas reguler dan kelas International Program (IP). Kelas reguler merupakan sarana bagi peserta didik untuk mengikuti kegiatan belajar mengajar dengan menggunakan Kurikulum 2013, sedangkan kelas IP yang mulai resmi beroperasisejak 24 November 2007 menggunakan Kurikulum Cambridge.

Secara garis besar, yang menjadi pembeda utama dari kelas reguler dan kelas IP adalah kurikulum yang digunakan.Kelas reguler menggunakan Kurikulum 2013 sedangkan kelas IP menggunakan Kurikulum Cambridge. Namun, peserta didik dari kelas IP juga memiliki hak yang sama untuk bisa mendapatkan ijazah SMP agar dapat digunakan untuk jenjang pendidikan selanjutnya sehingga pada akhirnya peserta didik dari kelas reguler maupun kelas IP akan sama-sama menghadapi ujian nasional.Berdasarkan kesamaan tersebut, maka digunakan hasil yang didapatkan peserta didik saat mengikuti ujian nasionalsebagai tolak ukur karena standar ujian nasional sudah ditetapkan oleh pemerintah pusat yang diatur dalam Peraturan Menteri Pendidikan dan Kebudayaan (Permendikbud) No. 20 tahun 2016 tentang Standar Kompetensi Lulusan Pendidikan Dasar dan Menengah (BSNP, 2016). Ketercapaian hasil ujian akhir tidak lepas dari penyelenggaraan program pendidikan di SMP Kristen Kalam Kudus Surakarta. Untuk mengetahui perbandingan ketercapaian hasil belajar antara program internasional dan reguler maka dilakukan penelitian di SMP Kristen Kalam Kudus Surakarta.

\section{METODE PENELITIAN}

Studi komparatif ini dilakukan di SMP Kristen Kalam Kudus Surakarta yang beralamat di Jl. A.M. Sangadji No.24, Gajahan, Ps. Kliwon, Kota Surakarta, Jawa Tengah, 57115.Dilaksanakan selama bulan Agustus - Oktober 2017 semester I tahun ajaran 2017/2018.Penelitian dilakukan dengan beberapa teknik pengumpulan data, antara lain: 


\section{Observasi}

Teknik observasi merupakan teknik yang digunakan untuk melakukan observasi terhadap kondisi sekolah dan proses pembelajaran pada mata pelajaran sebagai penunjang pembelajaran peserta didik dari masing-masing program kurikulum kelas reguler dan kelas internasional. Observasi (pra-penelitian) dilakukan pada bulan Agustus 2017.
Digunakanlembar observasi untuk mengamati kondisi sekolah dan proses pembelajaran pada mata pelajaran sebagai penunjang pembelajaran peserta didik dari masing-masing program kurikulum. Untuk menambah informasi, digunakan juga angket yang diberikan kepada beberapa guru pengampu mata pelajaran IPA secara acak di SMPK Kalam Kudus Surakarta.

Tabel 1. Kisi-Kisi Observasi Program Reguler dan Internasional

\begin{tabular}{|c|c|c|}
\hline No. & Kriteria & Indikator \\
\hline \multirow[t]{3}{*}{1} & Sarana dan & Ruang kelas \\
\hline & Prasarana & Laboratorium IPA \\
\hline & & Media pembelajaran IPA \\
\hline \multirow[t]{2}{*}{2} & Kompetensi & Lama mengajar (masa pengabdian) \\
\hline & Profesional Guru & $\begin{array}{l}\text { Model pembelajaran yang digunakan } \\
\text { Kualifikasi pendidikan guru IPA }\end{array}$ \\
\hline \multirow[t]{3}{*}{3} & Kurikulum & Kompetensi Dasar IPA \\
\hline & & Jumlah Jam Pertemuan (JP) IPA \\
\hline & & Referensi yang digunakan \\
\hline
\end{tabular}

\section{Dokumentasi}

Teknik dokumentasi merupakan teknik pengumpulan data dengan menggunakan dokumen sebagai sumber data. Dalam penelitian ini teknik dokumentasi digunakan untuk mendapatkan data sekunder hasil belajar peserta didik (hasil ujian nasional) mata pelajaran IPA dari tahun 2012, 2013, 2015 sampai 2017 di Sekolah Kristen Kalam Kudus, Surakarta.

\section{Teknik analisis data}

Teknik analisis data menggunakanteknik analisis kuantitatif untuk pengujian hasil ujian akhir IPA peserta didik SMPK Kalam Kudus,
Surakarta. Analisis data penelitian terdiri atas uji validitas dan uji reliabilitas lembar observasi. Analisis data diperoleh dengan Uji Homogenitas Kolmogorov-Smirnov dan Shapiro-Wilk, kemudian dilakukan Uji Mann-Whitney menggunakan program SPSS 16.0.

\section{HASIL DAN PEMBAHASAN}

\section{Hasil Ujian Akhir Nasional}

Berdasarkan data hasil ujian nasional yang diperoleh dari SMPK Kalam Kudus Surakarta pada tahun 2012, 2013, 2015 sampai 2017, didapatkan jumlah sampel untuk peserta didik program reguler sebanyak 718 data dan 131 data untuk 
peserta didik program internasional. Hasil analisis data menunjukkan bahwa rata-rata nilai ujian akhir nasional program reguler adalah 78.32 dan program internasional adalah 81.45.Penyajian data hasil ujian akhir nasional disajikan pada tabel 2 sebagai berikut:

Tabel 2. Rata-Rata Hasil Ujian Akhir Nasional tahun 2012-2017

\begin{tabular}{ccccc}
\hline Program & $\mathrm{N}$ & Rata-Rata & Standar Deviasi & Standar Error \\
\hline Reguler & 718 & 78.3245 & 11.44058 & 0.42696 \\
Internasional & 131 & 81.4504 & 9.78595 & 0.85500 \\
\hline
\end{tabular}

\section{Uji Prasyarat}

Uji prasyarat yang dilakukan meliputi uji homogenitas dan normalitas.Uji homogenitas dilakukan berdasarkan kriteria keputusanLevene sementara uji normalitas berdasarkan kriteria Shapiro-Wilk.Data tidak bersifat homogen karena nilai $\alpha<$ p.Sig yaitu $0.010<0.05$.Uji normalitas untuk program reguler menunjukkan nilai $\mathrm{P}$ sebesar 0.000 untuk Uji Shapiro-Wilk (sig. $<0.05$ ), artinya data tidak terdistribusi normal. Nilai P 0.004 untuk Uji ShapiroWilk (sig. < 0.05) pada program internasional, yang menunjukan bahwa data tidak terdistribusi normal.

\section{Uji Hipotesis}

Berdasarkan uji prasyarat didapatkan hasil bahwa data tidak tersebar secara normal dan rata-rata data tidak homogen, maka dilakukan uji hipotesis non parametrik berdasarkan keputusan MannWhitney.Uji Hipotesis MannWhitneymenunjukkan peringkat rata-rata untuk program reguler sebesar 414.90 dan peringkat rata-rata untuk program internasional sebesar 480.37.Nilai $\mathrm{P}$ uji kedua kelompok ini sebesar 0.005 (sig. < 0.05), maka dapat disimpulkan secara statistik terdapat perbedaan signifikan antara hasil ujian akhir nasional program reguler dan program internasional.

Tabel 5.Rerata Nilai Ujian Akhir Sekolah Program Reguler dan Internasional

\begin{tabular}{ccc}
\hline Program & $\mathrm{N}$ & Mean rank \\
\hline Reguler & 718 & 414.90 \\
Internasional & 131 & 480.37 \\
\hline
\end{tabular}

Tabel 6. Hasil Uji Mann-Whitney Ujian Akhir Nasional Tahun 2012-2017

\begin{tabular}{lr}
\hline Indikator & Hasil UN \\
\hline Mann-Whitney U & $3.978 \mathrm{E} 4$ \\
Wilcoxon W & $2.979 \mathrm{E} 5$ \\
Z & -2.816 \\
Asymp. Sig. (2-tailed) & 0.005 \\
\hline
\end{tabular}


Observasi Faktor yang Mempengaruhi

\section{Program Reguler dan Internasional}

Berdasarkan observasi dan angket didapatkan hasil bahwa tidak ada perbedaan yang jauh pada sarana, prasarana, kualitas tenaga pendidik, serta kurikulum yang digunakan antara program reguler dengan internasional. Berikut adalah tabel hasil rekapitulasi lembar observasi dan angket :

Tabel 6. Rekapitulasi Hasil Observasi Perbandingan Program Reguler dan Internasional

\begin{tabular}{cccccc}
\hline No. & \multicolumn{1}{c}{ Kriteria } & \multicolumn{2}{c}{ Skor } & \multicolumn{2}{c}{ Kategori } \\
\cline { 2 - 6 } 1 & $\begin{array}{l}\text { Reguler } \\
\text { Sarana dan }\end{array}$ & 3.67 & 4 & Reguler & Snternasional \\
Sangat Baik & Sangat Baik \\
2 & $\begin{array}{l}\text { Prasarana } \\
\text { Kompetensi } \\
\text { Profesional Guru }\end{array}$ & 2.33 & 3.33 & Buruk & Baik \\
3 & $\begin{array}{l}\text { Ketercapaian } \\
\text { Kurikulum }\end{array}$ & 3.33 & 3.67 & Baik & Sangat Baik \\
\hline
\end{tabular}

Keterangan :

$1.00-1.50=$ sangat buruk

$1.51-2.50=$ buruk

$2.51-3.30=$ baik

$3.51-4.00=$ sangat baik

\section{Perbandingan Hasil Ujian Nasional}

Berdasarkan analisis data, dapat disimpulkan bahwa terdapat perbedaan secara signifikan pada hasil akhir antara program internasional dan program reguler dari sekitar 6 tahun terakhir.Berdasarkan hasil rata-rata tersebut, hasil ujian nasional yang diraih peserta didik program internasional lebih tinggi dibandingkan program reguler.

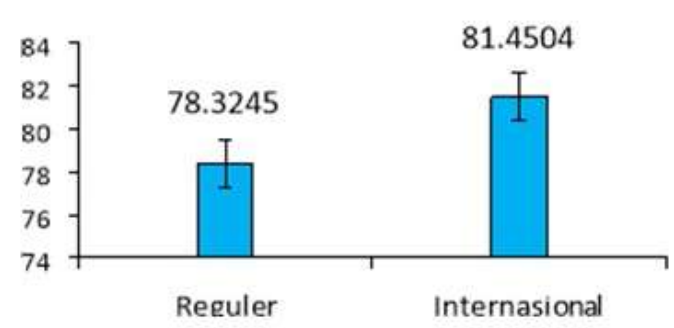

Gambar 1. Perbandingan Rata-Rata Hasil Ujian Nasional
Perbedaan kurikulum yang diterapkan pada masing-masing program menunjukan ketercapaian yang berbeda di akhir masa pembelajaran, Kurikulum Cambridge dengan pendekatan pemecahan masalah (problem solving) membuat peserta didik lebih mudah memahami pelajaran serta mengingat apa yang sudah dipelajari (Asqolani, 2016) sehingga mampu meraih hasil yang lebih tinggi dibandingkan dengan peserta didik program reguler. Penerapan metode pemecahan masalah pada pembelajaran IPA memang mampu meningkatkan hasil belajar (Ramadhan,dkk, 2016) dibandingkan metode ceramah.Dapat disimpulkan bahwa pemecahan masalah memberikan stimulus bagi siswa untuk dapat berpikir dengan pengetahuan mereka 
sendiri (berpikir konstruktif). Apabila mengalami peningkatan dibandingkan dibandingkan hasil rata-rata antar tahun program internasional yang cenderung pembelajaran, hasil yang diraih peserta turun seperti pada gambar di bawah ini. didik program reguler cenderung stabil dan

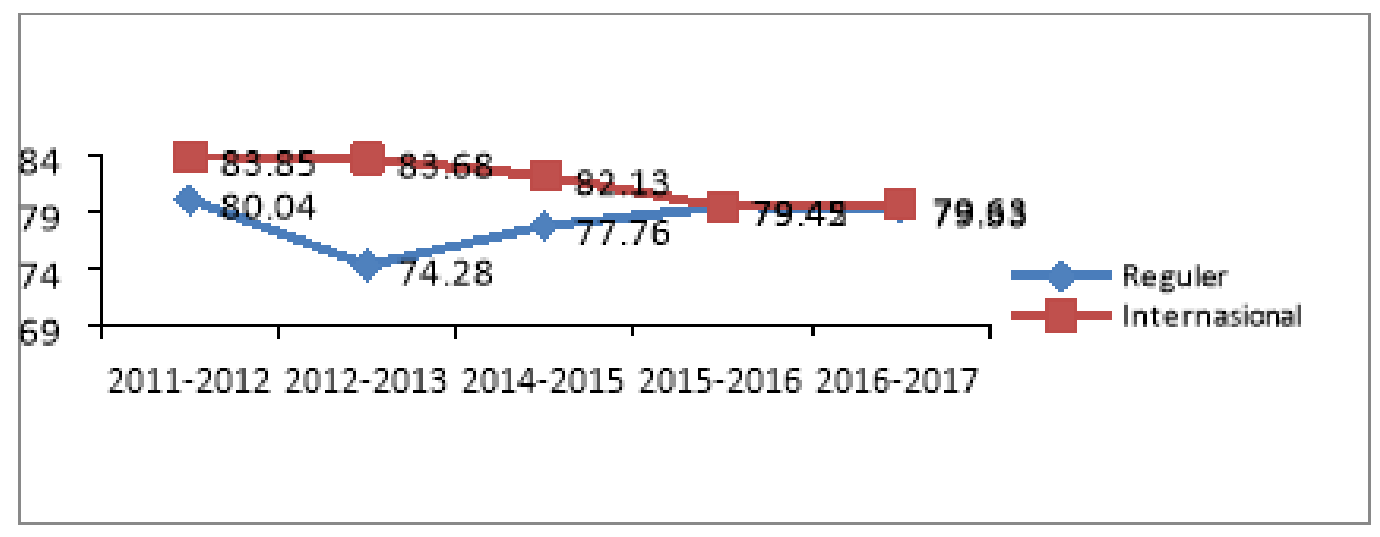

Gambar 2. Perbandingan Rata-Rata Hasil Ujian Nasional TiapTahun Ajaran

$\begin{array}{ccc}\text { Pergantian } & \text { kurikulum } & \text { yang } \\ \text { dicanangkan oleh } & \text { pemerintah } & \text { dari }\end{array}$

Kurikulum Tingkat Satuan Pendidikan (KTSP) menjadi Kurikulum 2013 juga memberi pengaruh pada ketercapaian hasil belajar peserta didik program reguler SMPK Kalam Kudus Surakarta karena

\section{Analisis Faktor Perbedaan Hasil Belajar}

Perbedaan ketercapaian hasil belajar peserta didik tak lepas dari faktor pendukung selama proses pembelajaran berlangsung. Beberapa faktor yang diperhatikan pada penelitian ini antara lain ketersediaan serta kelengkapan sarana-prasarana yang digunakan untuk proses pembelajaran, kompetensi profesional guru, dan ketercapaian penerapan kurikulum pada masing-masing program.
Kurikulum 2013 tidak hanya berfokus pada aspek kognitif, namun juga aspek psikomotorik dan afektif. Mulyoto (2013) menyampaikan bahwa keseimbangan aspek psikomotorik dan afektif akan mendukung peningkatan hasil belajar kognitif.

Berdasarkan hasil observasi dan angket yang dibagikan untuk menilai faktor pendukung proses pembelajaran dari masing-masing program dengan skala 1-4, didapatkan hasil untuk faktor sarana dan prasarana penunjang pembelajaran, program internasional mendapat skor 4 sedangkan program reguler mendapat skor 3.67. Pada penilaian kompetensi guru, program internasional mendapat skor 3.33 sedangkan program reguler mendapat skor 2.33.Faktor ketercapaian kurikulum 
program internasional mendapat skor 3.67 sedangkan program reguler mendapat skor 3.33. Berdasarkan hasil rekapitulasi tersebut dapat dilihat bahwa perolehan skor program internasional selalu lebih tinggi dibanding program reguler pada semua faktor.Rekapitulasi hasil angket dan observasi dapat dilihat pada gambar3.

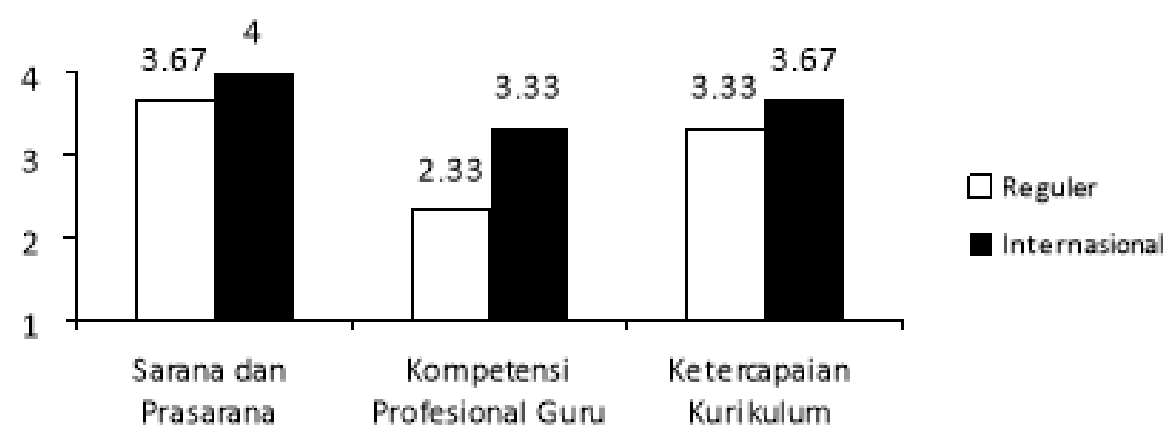

Gambar 3. Perbandingan Hasil Observasi dan Angket Program Reguler dan Internasional

Ketersediaan sarana dan prasarana yang baik secara kuantitas dan kualitas akan menunjang proses belajar peserta didik (Sundari, 2008). Faktor lain yang cukup penting yang mendukung ketercapaian hasil belajar agar lebih baik adalah kompetensi profesional guru, Mulyasa (2007) menyampaikan bahwa seorang guru harus mempunyai kepribadian luhur, memiliki kemampuan mengajar yang baik, serta memiliki ketrampilan dalam mengajar untuk mampu menguasai peserta didik di dalam kelas agar mampu menjadi fasilitator pembelajaran sehingga dapat meningkatkan hasil belajar peserta didik. Ketersediaan sarana dan prasarana yang memadai serta guru dengan kompetensi profesional yang baik akan mendukung faktor ketiga, yaitu ketercapaian kurikulum. Menurut Kunandar (2014), ketercapaian kurikulum yang diterapkan dapat dijadikan sebagai salah satu indikator penilaian autentik terhadap hasil belajar peserta didik. Semakin lengkap suatu standar dalam kurikulum dapat terpenuhi, diharapkan akan semakin meningkatkan hasil belajar yang diraih peserta didik. Ketiga faktor tersebut akan berpengaruh pada hasil belajar yang diraih peserta didik. Ketersediaan sarana prasarana pembelajaran, kompetensi guru yang baik, serta ketercapaian proses pembelajaran dalam menjawab kadar kompetensi dari kurikulum akan berbanding lurus dengan ketercapaian hasil belajar.

\section{KESIMPULAN DAN SARAN}

Berdasarkan studi komparasi yang sudah dilakukan, dapat disimpulkan bahwa terdapat perbedaan yang signifikan terhadap ketercapaian hasil belajar peserta didik dari 
program internasional dan reguler di SMPK

Kalam Kudus Surakarta dari tahun ajaran 2011-2012 hingga 2016-2017.Perbedaan signifikan tersebut terlihat dari hasil uji Mann-Whitney dengan nilai $\mathrm{P}$ uji kedua kelompok ini sebesar 0.005 (sig. < 0.05) dari rata-rata program internasional yaitu 81.4504 yang lebih besar dibandingkan rata-rata program reguler yaitu 78.3245 .

Perbedaan hasil belajar tersebut dipengaruhi oleh beberapa faktor seperti sarana prasarana, kompetensi profesional guru, dan ketercapaian kurikulum.Program internasional cenderung lebih baik dari ketiga faktor tersebut dibandingkan program reguler.Walaupun hasil rata-rata peserta didik dari program reguler lebih rendah dibandingkan internasional, hasil belajar yang diraih peserta didik program reguler memiliki tren lebih baik dibandingkan peserta didik dari program internasional yang cenderung mengalami penurunan rata-rata dari tahun ke tahun.

Berdasarkan penelitian yang sudah dilakukan, ada beberapa saran yang dapat dipertimbangkan untuk penelitian serupa di masa mendatang, yaitu :

1. Analisis perbedaaan ketercapaian hasil belajar tidak hanya ditinjau hasil ujian nasional, tapi juga hasil ujian lain misal ujian sekolah.

2. Perbedaaan ketercapaian hasil belajar dapat juga merujuk ada aspek afektif dan psikomotorik.
3. Penelitian lebih lanjut mengenai faktor yang mempengaruhi hasil belajar, bisa dari segi kualitas (penelitian lanjutan dari faktor yang digunakan pada studi komparasi ini) atau segi kuantitas (menambahkan faktor lain selain sarana prasarana, kompetensi profesional guru, dan ketercapaian kurikulum)

\section{DAFTAR PUSTAKA}

Asqolani.2016.Implementasi Kurikulum Cambridge di MI Mumtaza Pondok Cabe Pamulang Tangerang Selatan. Skripsi. Jurusan Manajemen Pendidikan, Fakultas Ilmu Tarbiyah dan Ilmu Keguruan. Universitas Islam Negeri Syarif Hidayatullah Jakarta

BSNP.2016. Standar Kompetensi Lulusan Pendidikan Dasar dan Menengah. Jakarta: Depdikbud.

Meilani, S. M. 2011. Pengantar Ilmu Pendidikan. Jakarta: Universitas Negeri Jakarta.

Mukminan. 2014. Tantangan Pendidikan di Abad 21.

(http://staffnew.uny.ac.id/upload/13 0682770/penelitian/ba-28-mkltpunnesatantangan-pddk-di-abad21.pdf). Diakses pada tanggal 20 Mei 2017.

Mulyasa, E. 2007.Standar Kompetensi dan Sertifikasi Guru. Bandung: Remaja Rosda Karya.

Mulyoto.2013. Strategi Pembelajaran di Era Kurikulum 2013. Jakarta: Prestasi Pustaka Raya.

Permendikbud.2012. Peraturan Menteri Pendidikan dan Kebudayaan tentang Standar Kompetensi Lulusan.

Ramadhan, G., E. Dzulkifly., dan T. Suratno. 2016. Penerapan Metode Problem Solving pada Pembelajaran IPA tentang Konsep Perubahan Kenampakan Bumi untuk Meningkatkan Hasil Belajar Siswa Kelas 4 SDN Taman. Jurnal Kalimaya. Nol. 4, No.2. 
Sa'ud, U. S. dan M. Sumantri.2007.Pendidikan Dasar dan Menengahdalam Ilmu dan Aplikasi Pendidikan : Bagian 4 Pendidikan Lintas Bidang. Bandung: Imperial Bhakti Utama.

Sundari, R. 2008. Evaluasi Pemanfaatan Laboratorium dalam Pembelajaran Biologi di Madrasah Aliyah Negeri Sekabupaten Sleman.Jurnal Penelitian dan Evaluasi. Vol. 2, No. $12,196-212$

Wuradji, H. 2015. Tantangan Pendidikan di Indonesia Menyosong Era Globalisasi dan Kemajuan IPTEK Abad 21. Jurnal Dinamika Pendidikan. No.: $11-24$ 